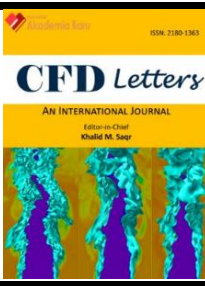

\title{
Numerical Study of Heat Transfer Enhancement for Mono and Hybrid Nanofluids Flow in a Straight Pipe
}

\author{
Azraf Azman ${ }^{1}$, Mohd Zamri Yusoff ${ }^{1}{ }^{,}$, Azfarizal Mukhtar ${ }^{1}$, Prem Gunnasegaran ${ }^{1}$, Nasri A. Hamid ${ }^{1}$, Ng \\ Khai Ching ${ }^{2}$ \\ UNITEN, Jalan IKRAM-UNITEN 43000 Kajang Selangor, Malaysia \\ University of Nottingham Malaysia Campus, Jalan Broga,43500 Semenyih, Selangor, Malaysia
}

\section{ARTICLE INFO}

\section{Article history:}

Received 24 December 2020

Received in revised form 15 February 2021

Accepted 23 February 2021

Available online 27 February 2021

\section{Keywords:}

Hybrid nanofluid; mixing ratio; volume

fraction; turbulent flow; Nusselt number

\section{ABSTRACT}

In recent years, there has been an increasing interest in heat transfer enhancement using nanofluids in channels due to current devices become smaller and more compact and are expected to perform better. Thus, we attempt to introduce hybrid nanofluids flow in a straight pipe using Ansys Fluent software. The simulation was prepared with certain specific parameters such as the hydraulic diameter is set at $10 \mathrm{~mm}$, the flow is a continuum, the Reynold number in the range of 5000 to $30000, k-\varepsilon$ turbulent model used in this simulation, the inlet temperature $297 \mathrm{~K}$, and the uniform temperature along the pipe at $313 \mathrm{~K}$. This study was carried out on $\mathrm{Al} 2 \mathrm{O} 3+\mathrm{Cu} /$ water hybrid nanofluids to analyse the thermal improvement and friction factor of nanofluids occur in a straight pipe. Then, the numerical results obtained were compared between mono and hybrid nanofluids. It was found that the mono nanofluids at $1 \%$ and $4 \%$ indicate a significant increase in Nusselt number at $17 \%$ and $24 \%$ respectively and hybrid nanofluid increase at $2 \%$ to $5.6 \%$ compared to base fluid. Whereas the friction factor remains similar for all the nanofluids. However, the performance evaluation criterion (PEC) has shown that hybrid nanofluids remain lower than mono nanofluids.

\section{Introduction}

The last few decades have witnessed vast research on new types of heat transfer fluids, namely nanofluids. Nanofluids are a fluid that contains nanometer-sized solid particles. This nanofluid was introduced by Choi and Eastman [1] and it has been proven to give better heat transfer efficiency compared to conventional fluids. Many applications of heat transfer enhancement using nanofluids are to meet the cooling challenge necessary such as the photonics, transportation, electronics, and energy supply industries [2-5]. Therefore, to improve the heat transfer enhancement, many designers and researchers have conducted heat transfer enhancement studies in the last decades.

\footnotetext{
* Corresponding author.

E-mail address: zamri@uniten.edu.my (Mohd Zamri Yusoff)
} 
Many heat transfer enhancement studies utilize various mono nanofluids types such as $\mathrm{Al}_{2} \mathrm{O}_{3}, \mathrm{CNT}$, $\mathrm{Cu}, \mathrm{Fe}_{2} \mathrm{O}_{3}, \mathrm{Ag}, \mathrm{CuO}, \mathrm{TiO}_{2}, \mathrm{SiO}_{2}, \mathrm{ZnO}$ and $\mathrm{SiC}$ through a tube have been done $[6,7]$.

Recent studies have focused on hybrid nanomaterial to find new nanofluids that render the highest heat transfer rates [8-12]. According to Sarkar et al., [13], hybrid nanofluids are a new sort of nanofluid that can be prepared by mixing two nanofluids, (i) by suspending different types (two or more) of nanoparticles in a base fluid, or (ii) by suspending hybrid (composite) nanoparticles in a base fluid. Suresh et al., [14] studied the two-step method adopting the technique of hydrogen reduction by using $\mathrm{Al}_{2} \mathrm{O}_{3}-\mathrm{Cu} /$ water hybrid nanofluids. The volume fraction of hybrid nanofluids were $0.1 \%$ and $2 \%$ and prepared by dispersing in deionized water. The results showed that the viscosity and thermal conductivity of the hybrid nanofluids increases with the increase of the nanoparticles volume fraction. Abdolreza et al., [15], numerically studied the Al2O3-Cu/water hybrid nanofluids flow in a straight pipe on laminar force heat transfer. The results showed an improvement of $4.73 \%$ and $13.46 \%$ compared to $\mathrm{Al}_{2} \mathrm{O}_{3}$ / water and water as base fluid respectively.

In this study, the CFD models were presented for fully developed turbulent flows in a uniformly heated straight pipe based on the single-phase model. The modelling was done considering 1 and 4 volume per cent of $\mathrm{Al}_{2} \mathrm{O}_{3}, \mathrm{Cu}$ and $\mathrm{Al}_{2} \mathrm{O}_{3}+\mathrm{Cu} /$ with three different mixing ratios 50:50, 60:40 and 40:60 dispersed in water as the base fluid. The objective of the present investigation is to estimate numerically the Nusselt number, friction factor and PEC in the turbulent flow of hybrid $\mathrm{Al}_{2} \mathrm{O}_{3}+\mathrm{Cu}$ /water nanofluid (ceramic based core and metallic base core) through a circular tube under constant heat flux condition for, as most flow in engineering application such as heat exchanger are turbulent flow and which no previous study has been reported in literature.

\section{Methodology}

\subsection{Thermophysical Properties of Mono and Hybrid Nanofluid}

These equations are general and can be applied in mono and hybrid nanoparticles with the suitable modifications, the base fluid is symbolized with (bf), the nanoparticle with (np) and the nanofluid with (nf), while the volume concentration of the total nanoparticle in the fluid with $(\varnothing)$. It is important to state that in this study, the nanoparticle " $\mathrm{Al}_{2} \mathrm{O}_{3}$ " is symbolized with the number " 1 " and the nanoparticle " $\mathrm{Cu}$ " with the number " 2 ". It is obvious that the total concentration for the hybrid nanofluid $(\varnothing)$ is the following

$\emptyset=\emptyset_{1}+\emptyset_{2}$

The density ( $\rho)$ of the equivalent nanoparticle is given as

$\rho_{n p}=\frac{\emptyset_{1} \rho_{n p-1}+\emptyset_{2} \rho_{n p-2}}{\emptyset}$

The specific heat capacity $\left(C p_{n p}\right)$ of the equivalent nanoparticles is given as

$C p_{n p}=\frac{\emptyset_{1} \rho_{n p-1} C p_{n p-1}+\emptyset_{2} \rho_{n p-2} C p_{n p-2}}{\rho_{n p} \emptyset}$

The thermal conductivity $\left(k_{n p}\right)$ of the equivalent nanoparticles is given as

$k_{n p}=\frac{\emptyset_{1} \cdot k_{n p-1}+\emptyset_{2} \cdot k_{n p-2}}{\emptyset}$ 
The density $\left(\rho_{n f}\right)$ of the hybrid nanofluid is given as

$\rho_{n f}=\rho_{b f} \cdot(1-\emptyset)+\rho_{n p} \cdot \emptyset$

The specific thermal capacity $\left(C p_{n f}\right)$ is given as

$C p_{n f}=\frac{\rho_{b f} \cdot(1-\emptyset)}{\rho_{n f}} \cdot C p_{b f}+\frac{\rho_{n p} \cdot(1-\emptyset)}{\rho_{n f}} \cdot C p_{n p}$

The thermal conductivity of the nanofluid $\left(k_{n f}\right)$ is calculated according to the Maxwell model [16]

$k_{n f}=k_{b f} \frac{k_{n p}+2 \cdot k_{b f}+2 .\left(k_{n p}-k_{b f}\right) . \varnothing}{k_{n p}+2 . k_{b f}-\left(k_{n p}-k_{b f}\right) . \varnothing}$

The nanofluid dynamic viscosity $(\mu)$ can be calculated according to the Brinkman model [17]

$\mu_{n f}=\frac{\mu_{b f}}{(1-\emptyset)^{2.5}}$

As shown in Table 1, water and nanoparticles properties is based on Sekrani and Poncet [18], Table 2 show the nanofluids properties after mixing with different percentage and ratios.

Table 1

Water and nanoparticles properties

\begin{tabular}{lllll}
\hline Materials & $\rho\left(\mathrm{kg} / \mathrm{m}^{3}\right)$ & $\mathrm{Cp}(\mathrm{J} / \mathrm{kg} . \mathrm{K})$ & $\mathrm{k}(\mathrm{W} / \mathrm{m} . \mathrm{K})$ & $\mu(\mathrm{Pa} \mathrm{s})$ \\
\hline Water & 998 & 4182 & 0.597 & 0.000998 \\
Alumina, Al2O3 & 3880 & 765 & 40 & - \\
Copper, $\mathrm{Cu}$ & 8954 & 383.1 & 386 & - \\
\hline
\end{tabular}

Table 2

Mono and hybrid nanofluids properties

\begin{tabular}{lllllll}
\hline Nanofluids & Volume fraction, $\phi \%$ (mixing ratio) & $\rho\left(\mathrm{kg} / \mathrm{m}^{3}\right)$ & $\mathrm{Cp}(\mathrm{J} / \mathrm{kg} \cdot \mathrm{K})$ & $\mathrm{k}(\mathrm{W} / \mathrm{m} \cdot \mathrm{K})$ & $\mu(\mathrm{Pa} \mathrm{s})$ & $\mathrm{Pr}$ \\
\hline $\mathrm{Al2O3}$ & 1 & 1025.83 & 4049.87 & 0.6235 & 0.00089 & 5.781 \\
& 4 & 1112.32 & 3702.65 & 0.65517 & 0.00139 & 7.856 \\
$\mathrm{Cu}$ & 1 & & & & & \\
& 4 & 1076.57 & 3863.289 & 0.6235 & 0.000891 & 5.521 \\
& & 1315.28 & 3145.35 & 0.65517 & 0.001389 & 6.668 \\
$\mathrm{Al} 2 \mathrm{O3}+\mathrm{Cu}$ & $1(60: 40)$ & & & & & \\
& $4(60: 40)$ & 1046.13 & 3973.10 & 0.63138 & 0.000872 & 5.487 \\
& $1(50: 50)$ & 1193.50 & 3456.98 & 0.68881 & 0.000941 & 4.723 \\
& $4(50: 50)$ & 1051.2 & 3954.33 & 0.63140 & 0.000872 & 5.461 \\
& $1(40: 60)$ & 1213.8 & 3400.70 & 0.68894 & 0.000941 & 4.645 \\
& $4(40: 60)$ & 1056.27 & 3935.77 & 0.63144 & 0.000872 & 5.435 \\
& & 1236.10 & 3346.27 & 0.68904 & 0.000941 & 4.570 \\
\hline
\end{tabular}

$h n f 40 r=40: 60, h n f 50 r=50: 50, h n f 60 r=60: 40$

As shown in Table 2, by increasing the $\mathrm{Cu}$ nanoparticle in hybrid nanofluid mixing ratio, the $\operatorname{Pr}$ decreased. This shows that these hybrid nanofluids is due to increase in viscosity higher than increase in thermal conductivity reported by Sidik [19]. The possible reasons for this reduction may be; (i) more interfacial resistance develop due to the lack of collaboration among hybrid particles, (ii) 
agglomeration rate in metallic nanofluids and the dispersion is degraded as reported by Babu et al., [20].

\subsection{CFD Set-up, Model Geometry and Mesh Generation}

In this study, the finite-volume based ANSYS Fluent V19.2 software was used to solve the Reynolds Average Navier-Stokes (RANS) equations that govern the turbulent fluid flow motion in the straight pipe as shown in Figure 1 is the model geometry and in Table 3 is the geometrical parameters. Then, the model was discretized using quadrilateral mesh as seen in Figure 2, where finer mesh was generated around the critical areas such as at near wall at the straight pipe.

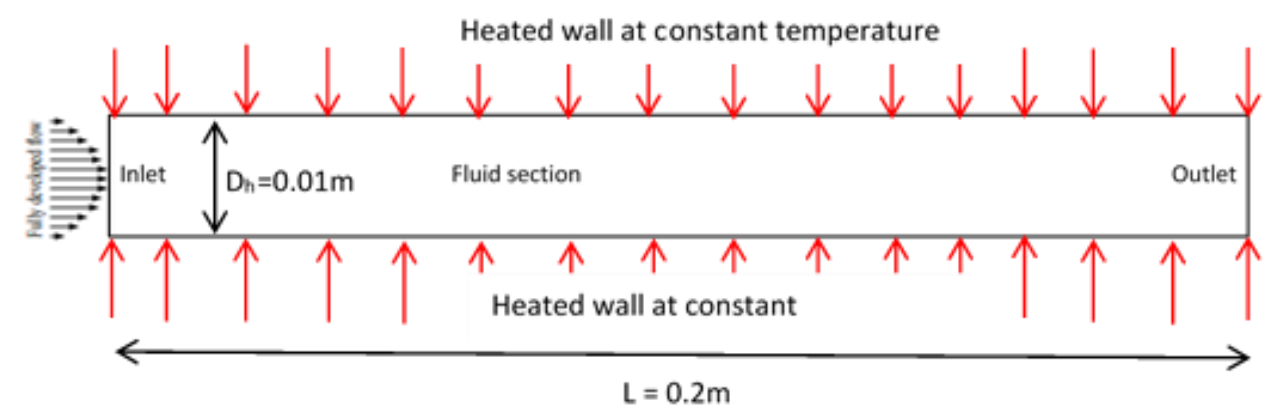

Fig. 1. Schematic diagram of computational domain

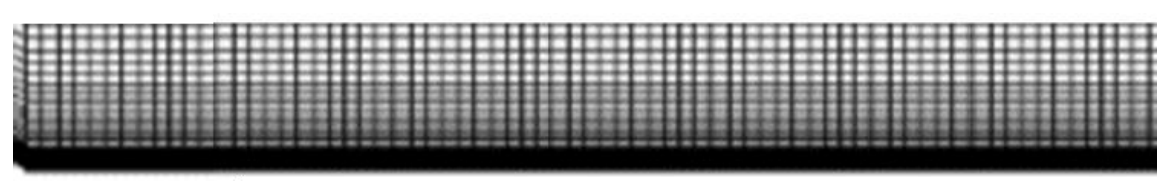

Fig. 2. Discretized structured mesh of computational domain

Table 3

Geometrical parameters

\begin{tabular}{ll}
\hline Parameters & Range $(\mathrm{m})$ \\
\hline Hydraulic diameter, $\mathrm{D}_{\mathrm{h}}$ & 0.01 \\
Pipe length, $\mathrm{L}$ & 0.2 \\
\hline
\end{tabular}

An inflation was applied near the wall, the inflation value was calculated by assuming the fluid is at sub viscous layer, $y^{+=1}$ using Eq. (9) and the first layer height was calculated using Eq. (10).

$y^{+}=\frac{y U_{\tau}}{v}$

$y=\frac{y^{+} v}{U_{\tau}}$

where $y$ is the normal distance from the wall and the first layer height value is, $y=0.02 \mathrm{~mm}$ and 20 layers maximum were applied with the growth rate of 1.2.

Single phase concepts with uniformed conditions were enabled. Various properties of nanofluids were given as input, including density, thermal conductivity, specific heat and viscosity. The behaviour of the fluid was considered to be continuous in nature, the preliminary governing equations include continuity, momentum and energy for turbulent flow conditions. These equations are as follows 
Conservation of mass

$\frac{\partial\left(\rho u_{i}\right)}{\partial x_{i}}=0$

Conservation of momentum

$\frac{\partial}{\partial x_{i}}\left(\rho u_{i} u_{j}\right)=-\frac{\partial P}{\partial x_{i}}+\frac{\partial}{\partial x_{j}}\left[\mu\left(\frac{\partial u_{i}}{\partial x_{j}}+\frac{\partial u_{j}}{\partial x_{j}}\right)-\frac{2}{3} \mu \frac{\partial u_{i}}{\partial x_{i}} \delta_{i j}-\overline{\rho u_{\imath}^{\prime} u_{J}^{\prime}}\right]$

Conservation of energy

$\frac{\partial}{\partial x_{i}}\left(\rho u_{j} C_{p} T\right)=-\frac{\partial}{\partial x_{i}}\left(\lambda \frac{\partial T}{\partial x_{j}}+\frac{\mu_{t}}{\sigma_{h, t}} \frac{\partial\left(C_{p} T\right)}{\partial x_{j}}\right)+u_{j} \frac{\partial P}{\partial x_{j}}+\left[\mu\left(\frac{\partial u_{i}}{\partial x_{j}}+\frac{\partial u_{j}}{\partial x_{j}}\right)-\frac{2}{3} \mu \frac{\partial u_{i}}{\partial x_{i}} \delta_{i j}-\overline{\rho u^{\prime}{ }_{\imath} u_{J}^{\prime}}\right] \frac{\partial u_{i}}{\partial x_{j}}$

where $-\overline{\rho u^{\prime}{ }_{l} u^{\prime}}$ are the Reynolds stress, $u_{i}$ and $u_{j}$ are the time-averaged velocity for $i$ and $j$ directions. Time-averaged temperature, fluid thermal conductivity, density, turbulent Prandtl number for energy, turbulent viscosity and time-averaged pressure are stated as $T, \lambda, \rho, \sigma_{\mathrm{h}, \mathrm{t}}, \mu_{\mathrm{t}}$ and $P$, respectively.

In the numerical study, the reliazable $k-\varepsilon$ turbulence model is used in order to give fast and accurate results $[20,21]$. Therefore, turbulent dissipation rates $(\varepsilon)$ and transport of turbulence kinetic energy $(k)$ equations should be considered.

$k$ equation

$\frac{\partial}{\partial x_{j}}\left(\rho k u_{j}\right)=\frac{\partial}{\partial x_{i}}\left[\left(\mu+\frac{\mu_{t}}{\sigma_{k}}\right) \frac{\partial k}{\partial x_{j}}\right]+G_{k}-\rho \varepsilon$

$\varepsilon$ equation

$\frac{\partial}{\partial x_{j}}\left(\rho \varepsilon u_{j}\right)=\frac{\partial}{\partial x_{i}}\left[\left(\mu+\frac{\mu_{t}}{\sigma_{\varepsilon}}\right) \frac{\partial \varepsilon}{\partial x_{j}}\right]+\rho C_{1} S \varepsilon-\rho C_{2} \frac{\varepsilon^{2}}{k+\sqrt{v \varepsilon}}$

Turbulent Prandtl number is expressed as $\sigma_{k}$ and $\sigma_{\varepsilon}$ regarding $k$ and $\varepsilon$ in Eq. (14) and (15). Eq. (16) represents the turbulent viscosity.

$\mu_{t}=\rho C_{\mu} \frac{k^{2}}{\varepsilon}$

with $C_{1}=1.44, C_{2}=1.9, \sigma_{k}=1, \sigma_{\varepsilon}=1.2$

\subsection{Boundary Conditions}

The mono and hybrid nanofluids' volume concentrations ( $1 \%$ \& $4 \%$ ) at $297 \mathrm{~K}$ base temperature is used as an input. CFD analysis has been performed with a uniform velocity profile at the inlet and pressure outlet conditions used at the outlet of the pipe. The walls of the tube are assumed to be perfectly smooth and the constant temperature condition is specified on the tube wall with a value of $313 \mathrm{~K}$. The Reynolds number varied from 5,000 to 30,000 at each step of the iterations as the input data. The friction factor and the Nusselt number are introduced as the output data. 


\subsection{Computational Method}

The computations are carried out by solving the governing conversation equations along with the boundary conditions. The Finite Volume Method (FVM) is used to discretize the governing equations, and the SIMPLE algorithm is utilized to couple the pressure-velocity system based on Zainal et al., [22]. In order to achieve a more precise numerical solution, the second order upwind scheme is selected for the convective terms. Before proceeding with the computations, the appropriate convergence criteria are obtained. It is done by taking different convergence criteria and checking the difference.

The simulation was then executed for approximately 9000 iterations in order to attain a convergence solution. The solution was considered to be converged when there were no more obvious fluctuations in velocity, energy and the turbulence variables (the scaled residual RMS errors decreased to $10^{-6}$ ) as well as the domain has a net imbalance of less than $1 \%$. Grid Independent has been tested in ANSYS FLUENT for mesh sizes according to Figure 3. To find the most suitable mesh size, grid independent tests are performed for physical models. In this study, grid independence is examined using different mesh sizes, and for water.

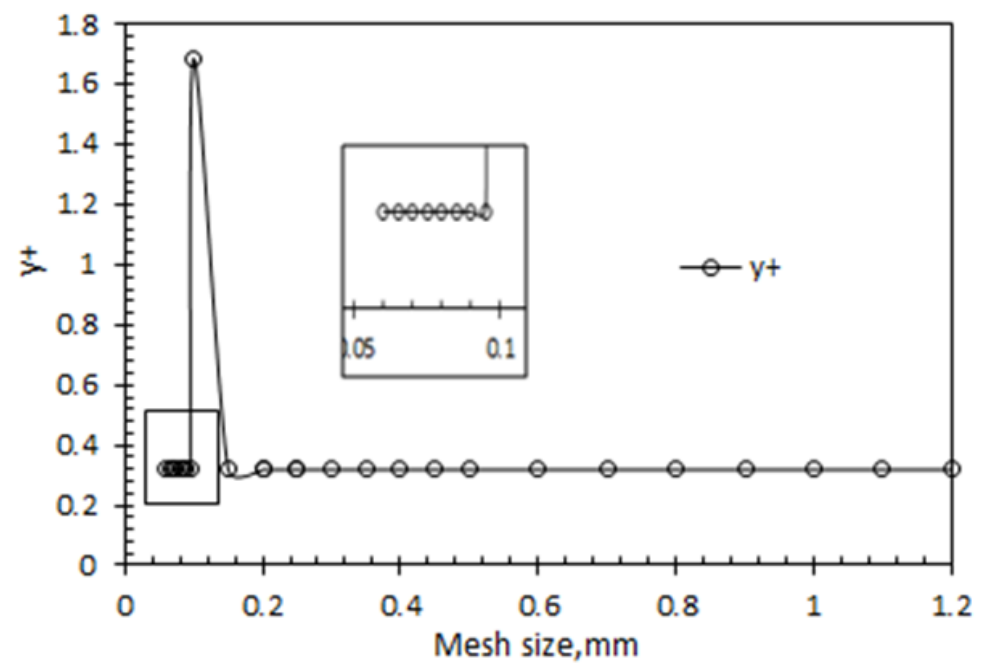

Fig. 3. Grid independent test of $y+$

\subsection{Boundary Layer y+ Value and Grid Independent Test}

The preferred procedure for determining the most accurate mesh is to carry out test runs on different mesh sizes and configurations until the numerical solution converges, in what is termed the grid independence test. Evidently, this requires a lot of time and computational effort. Turbulent flows are significantly affected by the presence of walls, where the viscosity-affected regions have large gradients in the solution variables and accurate presentation of the near wall region determines successful prediction of wall bounded turbulent flows. A strategy using the computed wall $y+$ is recommended when dealing with such flows. The wall $y+$ is a non-dimensional distance similar to local Reynolds number, often used in CFD to describe how coarse or fine a mesh is for a particular flow. It is the ratio between the turbulent and laminar influences in a cell. Accurate presentation of the flow in the near-wall region determines successful prediction of wall-bounded turbulent flows. The computation domain as illustrated in Figure 1 and mesh sizes are applied to the computation domain based on the $\mathrm{Y}+$ calculation. To determine successfully prediction for wall-bounded turbulent flows, the $y+\approx 1$ are most desirable for near-wall modelling according to Salim and Cheah [23]. 
In Figure 3(a), y+ value for water is 0.31866 , for mono and hybrid nanofluids in between 0.3199 to 0.3203 at $R e=5000$. The $y+$ value for mono and hybrid nanofluids slightly increase compared to water, due to viscosity. Different viscosity influences the y+ value according to Manjunatha et al., [24]. Figure 4(b), shows that the $y+$ increases when the Re increases.

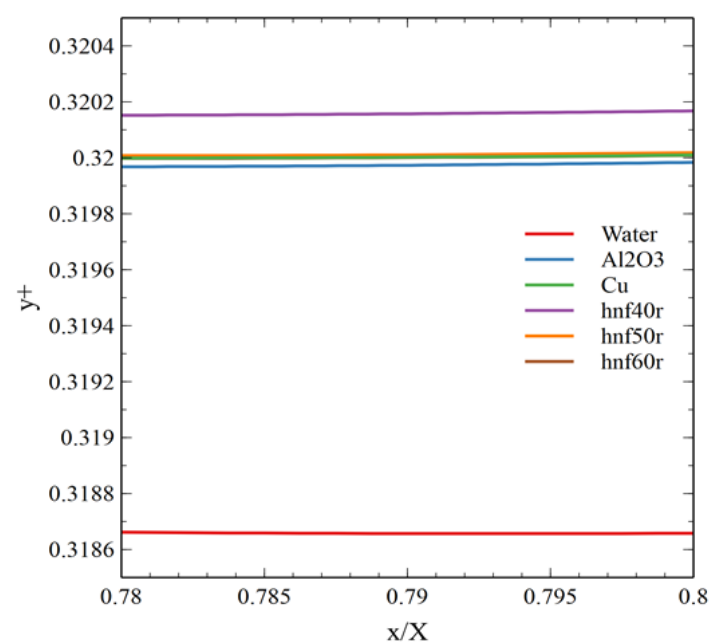

(a)

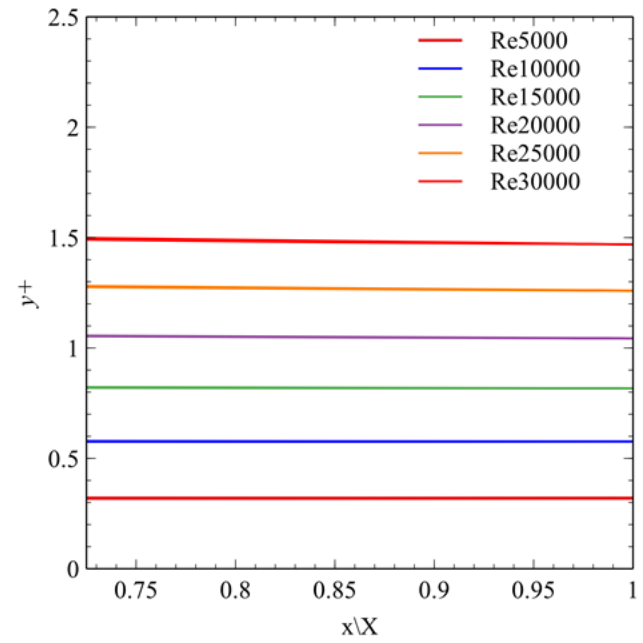

(b)

hnf__r represents the hybrid nanofluid ratio and the ratios are $h n f 40 r=40: 60, h n f 50 r=50: 50$ and $h n f 60 r=60: 40$

Fig. 4. Validation of $y+$ value for straight pipe model at $R e=5000$

\section{Results}

The present computations are performed for a 2-D turbulent flow of the $\mathrm{Al}_{2} \mathrm{O}_{3}$-water nanofluid over the smooth pipe. As presented in Table 2, mono and hybrid parameters are considered. Various forms of quantitative and qualitative results can be displayed from the output of simulations, but due to the space restriction only some of these results are presented. The thermal-hydraulic performance is presented in terms of Nusselt number and Darcy friction factor, and the optimal working fluid is obtained using the considered Performance Evaluation Criterion (PEC), Eq. (17). It should be noted, when specific solution is studied, the other associated parameters are kept constant.

$P E C=\frac{\left(N u_{E} / N u_{N E}\right)}{\left(f_{E} / f_{N E}\right)^{1 / 3}}$

To validate the numerical method used in the study, the Nusselt number and friction factor for the water flow in a straight channel is calculated and compared with Dittus-Boelter, Eq. (18), and Petukhov, Eq. (19), correlations (for Nusselt number) and Filonenko, Eq. (20), and McAdams, Eq. (21), correlations (for friction factor).

$N u=0.024 R e^{0.8} \operatorname{Pr}^{0.4}$

$N u=\frac{\operatorname{RePr}\left(\frac{f}{8}\right)}{1.07+12.7\left(\frac{f}{8}\right)^{0.5}\left(\operatorname{Pr}^{\frac{2}{3}}-1\right)}$

$f=\left(1.84 \log _{10} R e-1.64\right)^{-2}$

$f=0.18 R e^{-2}$ 
As illustrated in Figure 5(a) and (b), the present work shows a good trend agreement with the empirical correlation data. The average error for $\mathrm{Nu}$ and friction factor is $0.6 \%$ to $8 \%$ and $4.43 \%$ respectively.

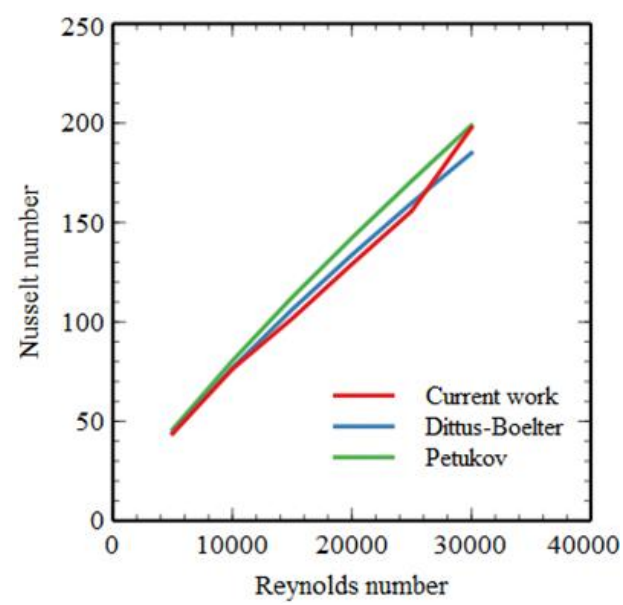

(a)

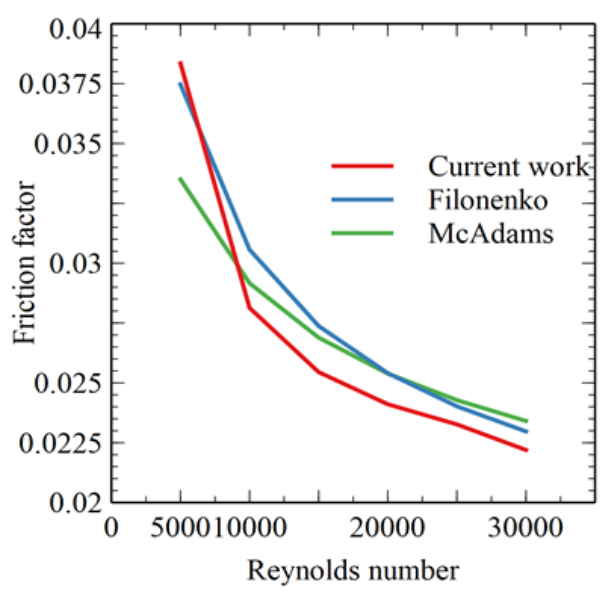

(b)

Fig. 5. (a) Nusselt number and (b) friction factor of water

The considered correlations for the $\mathrm{Al}_{2} \mathrm{O}_{3}$-water nanofluid flowing in the straight channel are Eq. (22), and Eq. (23).

$N u=0.021 \operatorname{Re}^{0.8} \operatorname{Pr}^{0.5}$

$N u=0.085 \operatorname{Re}^{0.71} \operatorname{Pr}^{0.35}$

As illustrated in Figure 6(a) and (b), the comparisons show a good trend agreement between the present numerical results and the empirical correlations data. The average error for $\mathrm{Nu}$ at $1 \%$ and $4 \%$ is $17 \%$ and $24 \%$ respectively. The deviation may be related to different properties of $\mathrm{Al}_{2} \mathrm{O}_{3}$ used as an input data in the simulation. Therefore, the increase in viscosity with the increase of volume concentration may increase the deviation of the results.

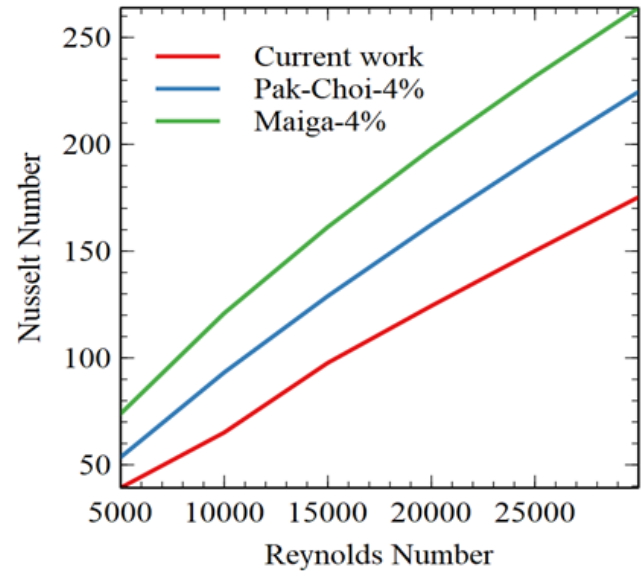

(a)

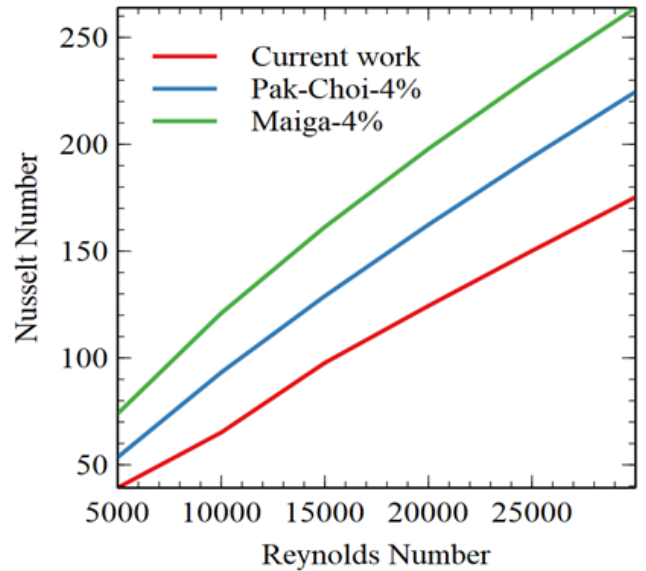

(b)

Fig. 6. Nusselt number of $\mathrm{Al}_{2} \mathrm{O}_{3}$-water nanofluids with nanoparticle volume fraction of (a) $1 \%$ and (b) $4 \%$ 


\subsection{Analysis of Heat Transfer and Flow Characteristics \\ 3.1.1 Comparison of Nusselt number of mono nanofluids}

Nusselt ( $\mathrm{Nu}$ ) number, friction factor and PEC values of Al2O3-water and $\mathrm{Cu}$-water nanofluid are plotted in Figure 7. As predicted in Figure 7(a), the Nu increased as the Re number increased, in volume concentration compared to water. The increase is between $3.65 \%$ to $15 \%$ for $\mathrm{Al}_{2} \mathrm{O}_{3}$-water and $2.4 \%$ to $10 \%$ for Cu-water compared to water. Moreover, the $\mathrm{Al}_{2} \mathrm{O}_{3}$-water nanofluid has higher Nu compared to Cu-Water nanofluid. It can be observed that the Nu increases with the increased in volume concentration. The results are consistent with the numerical results of Aghei et al., [25]. In other words, the Nu for the straight pipe considered increases with Re due to an increasing fluid thermal conductivity. Flow issues are related to increasing velocity, which increases heat transfer.

Figure 7(b) shows the friction factor vs Reynolds number for all the mono nanofluids. The friction factor decreases with the increase of Re. The friction factor shows quite similar results and trend for mono nanofluids and obviously the nanoparticles have a small effect in the flow field according to Kalteh et al., [26].

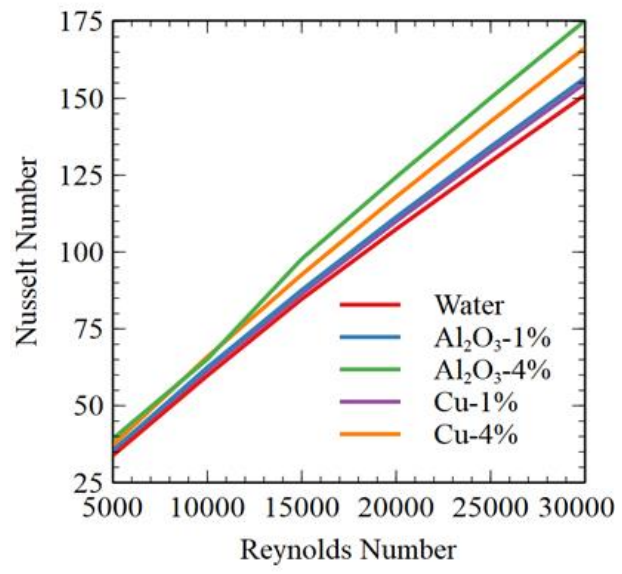

(a)

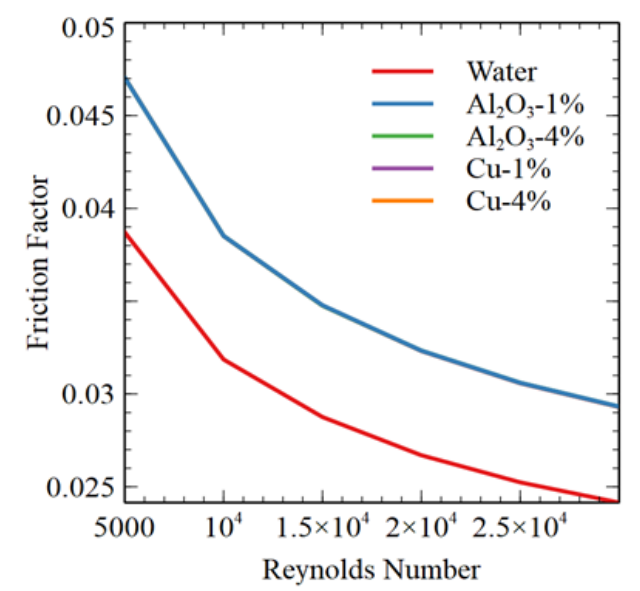

(b)

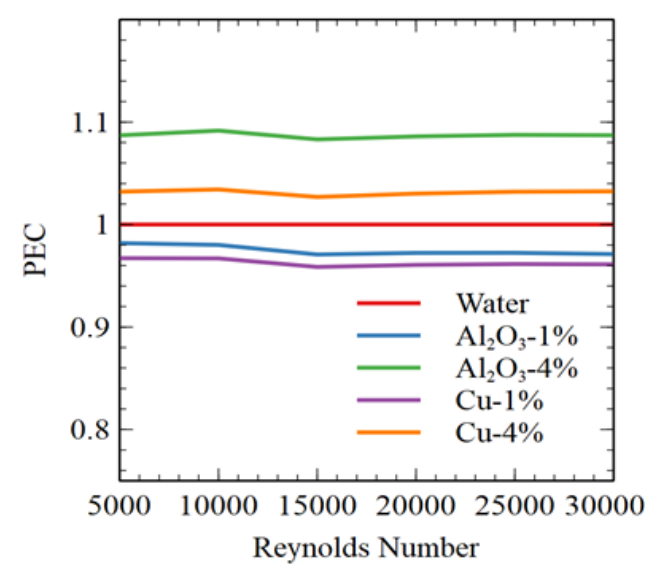

(c)

Fig. 7. Comparison of (a) Nu, (b) friction factor and (c) PEC, for mono nanofluids at $1 \%$ and $4 \%$ volume concentration of straight pipe

$\mathrm{Al}_{2} \mathrm{O}_{3}$-water and $\mathrm{Cu}$-water nanofluids with $4 \%$ concentration have higher value compared to $\mathrm{Al}_{2} \mathrm{O}_{3}$-water and $\mathrm{Cu}$-water at $1 \%$ concentration as shown in Figure 7 (c). However, for $1 \%$ for $\mathrm{Al}_{2} \mathrm{O}_{3}$ and $\mathrm{Cu}$ nanoparticles is below by $4 \%$ from the reference value of water performance for $\mathrm{Re}=5000$ to 
$\mathrm{Re}=30000$. According to Rashidi et al., [27], a value of PEC which is greater than unity is suitable for heat transfer augmentation specifically for this current study.

\subsubsection{Comparison of Nusselt number of hybrids nanofluids}

The $\mathrm{Nu}$ increases with Re for hybrid nanofluids with $1 \%$ concentration as shown in Figure 8 (a). The ratios of the hybrid nanofluids are slightly higher than water.

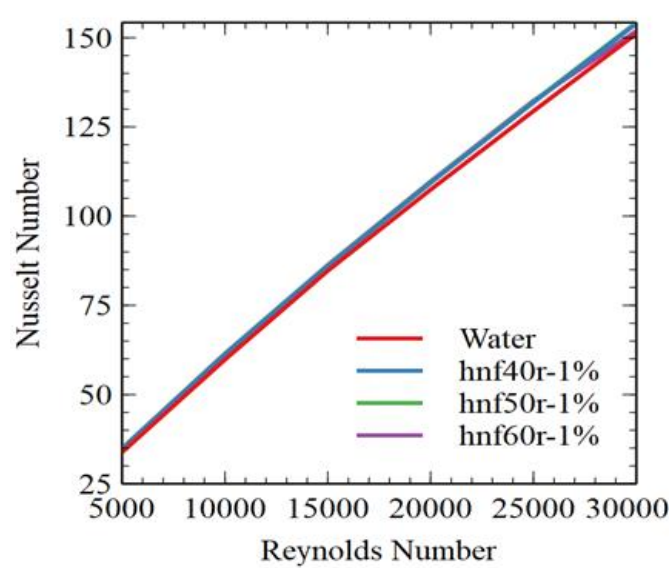

(a)

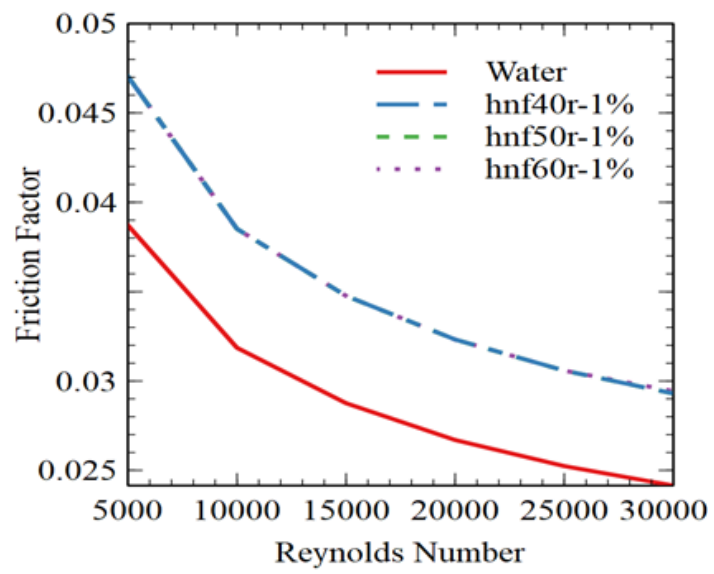

(c)

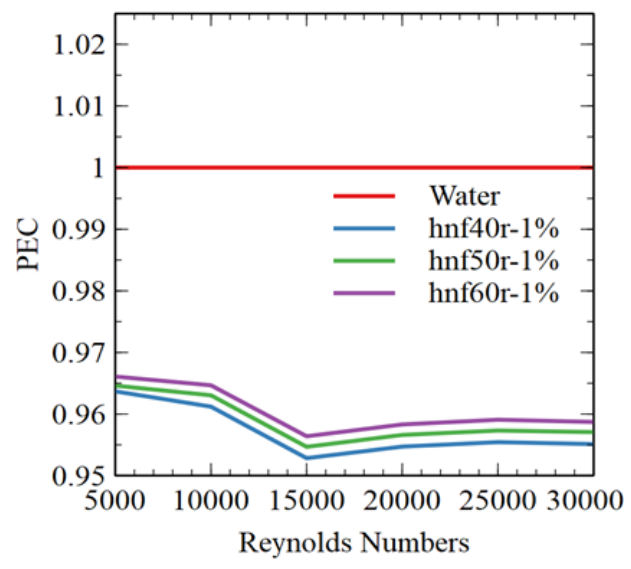

(e)

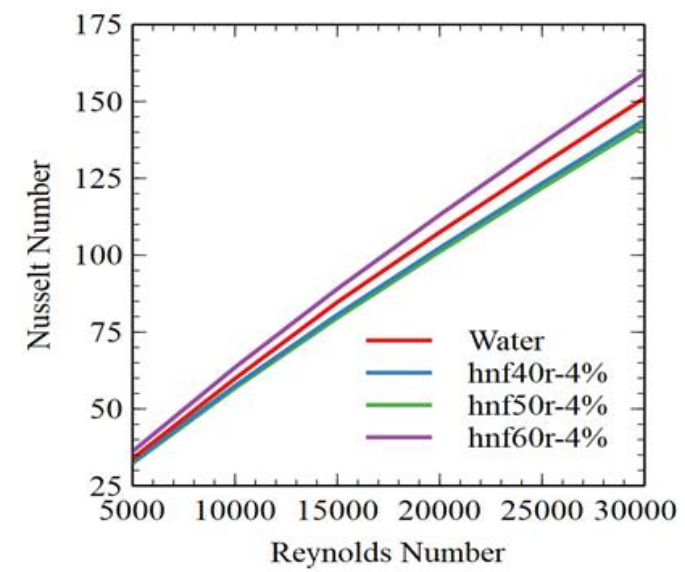

(b)

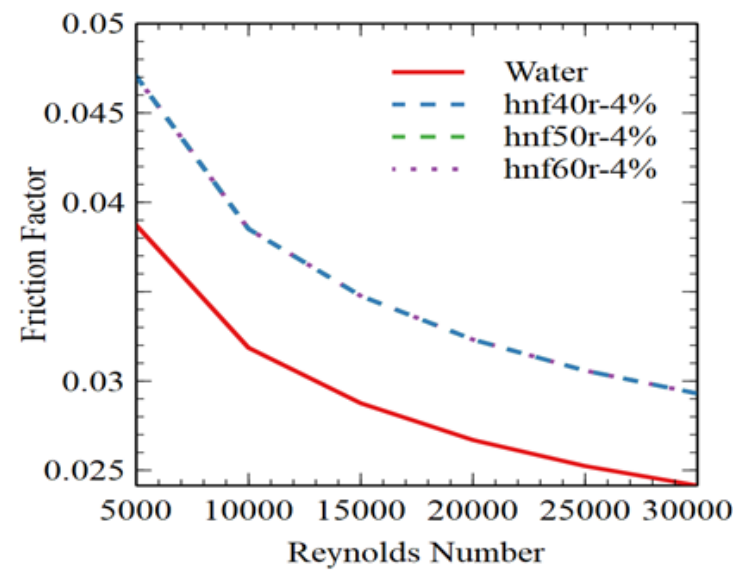

(d)

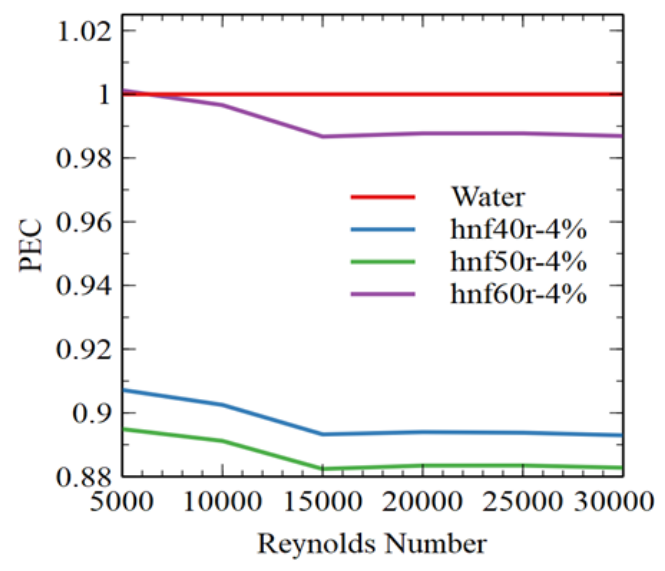

(f)

Fig. 8. Comparison of (a)-(b) for $\mathrm{Nu}$, (c)-(d) for friction factor, (e)-(f) for PEC, for hybrid nanofluids at $1 \%$ and $4 \%$ of straight pipe 
The Nu improved up to $2.3 \%$ for each of the ratios. In Figure $8(\mathrm{~b})$ shows that the Nu at $4 \%$ volume concentration of hybrid nanofluids shows some differences between the ratios. Hybrid of 60:40 ratio is slightly higher than the reference fluid compared to 50:50 and 40:60 ratios. The 60:40 ratio is higher by $5.3 \%$ and ratios of $50: 50$ and $40: 60$ slightly lower in the range of $3 \%$ to $5.7 \%$ compared to water.

Figure 8 (c) and (d), the friction factor for volume concentration of $1 \%$ and $4 \%$ higher compared to the reference fluid. It is obvious that the friction factor decreased when the Re increases along the straight pipe. The Figure 8 (c) and (d) shows a $20 \%$ increased for each of the volume concentration and ratios of the hybrid nano fluids compared to the reference fluids. The decreasing trends are in good agreement with most of the work done by other researchers.

A Performance Evaluation Criterion (PEC) is adopted in order to compare the thermal and fluiddynamic performance of the straight pipe with different nanofluids as reported by KhoshvaghtAliabadi [28]. Figure 8(e) and (f), shows the PEC for the hybrid nanofluids is lower than the reference fluid both for 15 and $4 \%$ volume concentration. For 1\%, the percentage difference is about $4.3 \%$, $5.9 \%$ and $4.5 \%$ for ratios of $50: 50,60: 40$ and $40: 60$ respectively. Hybrid nanofluids with $4 \%$ concentration shows that the PEC is below the reference fluid and it is $11.72 \%, 1.3 \%$ and $10.70 \%$ for 50:50, 60:40 and 40:60 ratios respectively.

\section{Conclusions}

In this article, the effect of mono and hybrid nanofluid types $\left(\mathrm{Al}_{2} \mathrm{O}_{3}\right.$-water, $\mathrm{Cu}$-water and $\mathrm{Al} 2 \mathrm{O} 3+\mathrm{Cu} /$ water) with two different nanoparticle volume fractions ( $\phi=1.0$ and $4.0 \%)$ on the straight pipe efficiency is numerically discussed by considering two-dimensional turbulent flow conditions. The results of the numerical study can be compiled as follows

I. The use of different mono nanofluid types and hybrid nanofluids with different mixing ratios has provided a great advantage in terms of convective heat transfer. It is noticed that convective heat transfer is enhanced by approximately $3.9 \%$ to $14.6 \%$ for mono nanofluids and $2 \%$ to $5.6 \%$ for hybrid nanofluids compared to base fluid.

II. As the volume fraction of nanoparticles increases, the convective heat transfer enhances, too.

III. The friction factor increases with the using of hybrid nanofluids. It is noticed that an increase of $20 \%$ for all the mixing ratios for all Re.

IV. The Darcy friction factor for mono and hybrid nanofluids has almost the same value. These mono and hybrid nanofluids have higher friction factor compared to water, consistently at $20 \%$ difference for all Re.

V. Heat transfer performance of mono nanofluids in comparison with their friction factor due to the PEC number is greater than 1.

\section{Acknowledgement}

The authors are grateful for the support from IAEA Research Contract No.18272 (CRP Grant), Universiti Tenaga Nasional (UNITEN), Agensi Nuklear Malaysia (ANM) and Jabatan Perkhidmatan Awam Malaysia (JPA) for their supports and helps in completing this work.

\section{References}

[1] Choi, S. US, and Jeffrey A. Eastman. Enhancing thermal conductivity of fluids with nanoparticles. No. ANL/MSD/CP84938; CONF-951135-29. Argonne National Lab., IL (United States), 1995.

[2] Hussein, Adnan M., K. V. Sharma, R. A. Bakar, and K. Kadirgama. "The effect of nanofluid volume concentration on heat transfer and friction factor inside a horizontal tube." Journal of Nanomaterials 2013 (2013).

https://doi.org/10.1155/2013/859563 
[3] Hussein, Adnan M., K. V. Sharma, R. A. Bakar, and K. Kadirgama. "A review of forced convection heat transfer enhancement and hydrodynamic characteristics of a nanofluid." Renewable and Sustainable Energy Reviews 29 (2014): 734-743.

https://doi.org/10.1016/i.rser.2013.08.014

[4] Hussein, Adnan M., K. V. Sharma, R. A. Bakar, and K. Kadirgama. "The effect of cross sectional area of tube on friction factor and heat transfer nanofluid turbulent flow." International Communications in Heat and Mass Transfer 47 (2013): 49-55.

https://doi.org/10.1016/i.icheatmasstransfer.2013.06.007

[5] Meibodi, Majid Emami, Mohsen Vafaie-Sefti, Ali Morad Rashidi, Azadeh Amrollahi, Mohsen Tabasi, and Hossein Sid Kalal. "An estimation for velocity and temperature profiles of nanofluids in fully developed turbulent flow conditions." International Communications in Heat and Mass Transfer 37, no. 7 (2010): 895-900. https://doi.org/10.1016/i.icheatmasstransfer.2010.03.012

[6] Ny, G., N. Barom, S. Noraziman, and S. Yeow. "Numerical study on turbulent-forced convective heat transfer of $\mathrm{Ag} / \mathrm{Heg}$ water nanofluid in pipe." Journal of Advanced Research in Materials Science 22, no. 1 (2016): 11-27.

[7] Wang, Jianli, Jianjun Zhu, Xing Zhang, and Yunfei Chen. "Heat transfer and pressure drop of nanofluids containing carbon nanotubes in laminar flows." Experimental Thermal and Fluid Science 44 (2013): 716-721.

https://doi.org/10.1016/i.expthermflusci.2012.09.013

[8] Pak, Bock Choon, and Young I. Cho. "Hydrodynamic and heat transfer study of dispersed fluids with submicron metallic oxide particles." Experimental Heat Transfer an International Journal 11, no. 2 (1998): 151-170. https://doi.org/10.1080/08916159808946559

[9] Hussein, Adnan M., Rosli Abu Bakar, K. Kadirgama, and Korada Viswanatha Sharma. "Heat transfer enhancement using nanofluids in an automotive cooling system." International Communications in Heat and Mass Transfer 53 (2014): 195-202. https://doi.org/10.1016/j.icheatmasstransfer.2014.01.003

[10] Sharma, K. V., L. Syam Sundar, and P. K. Sarma. "Estimation of heat transfer coefficient and friction factor in the transition flow with low volume concentration of Al2O3 nanofluid flowing in a circular tube and with twisted tape insert." International Communications in Heat and Mass Transfer 36, no. 5 (2009): 503-507. https://doi.org/10.1016/j.icheatmasstransfer.2009.02.011

[11] Hussein, Adnan M., R. A. Bakar, K. Kadirgama, and K. V. Sharma. "Heat transfer augmentation of a car radiator using nanofluids." Heat and Mass Transfer 50, no. 11 (2014): 1553-1561.

https://doi.org/10.1007/s00231-014-1369-2

[12] Kim, Doohyun, Younghwan Kwon, Yonghyeon Cho, Chengguo Li, Seongir Cheong, Yujin Hwang, Jaekeun Lee, Daeseung Hong, and Seongyong Moon. "Convective heat transfer characteristics of nanofluids under laminar and turbulent flow conditions." Current Applied Physics 9, no. 2 (2009): e119-e123. https://doi.org/10.1016/i.cap.2008.12.047

[13] Sarkar, Jahar, Pradyumna Ghosh, and Arjumand Adil. "A review on hybrid nanofluids: recent research, development and applications." Renewable and Sustainable Energy Reviews 43 (2015): 164-177.

https://doi.org/10.1016/i.rser.2014.11.023

[14] Suresh, S., K. P. Venkitaraj, P. Selvakumar, and M. Chandrasekar. "Synthesis of Al2O3-Cu/water hybrid nanofluids using two step method and its thermo physical properties." Colloids and Surfaces A: Physicochemical and Engineering Aspects 388, no. 1-3 (2011): 41-48. https://doi.org/10.1016/i.colsurfa.2011.08.005

[15] Moghadassi, Abdolreza, Ehsan Ghomi, and Fahime Parvizian. "A numerical study of water based Al2O3 and Al2O3Cu hybrid nanofluid effect on forced convective heat transfer." International Journal of Thermal Sciences 92 (2015): 50-57.

https://doi.org/10.1016/j.ijthermalsci.2015.01.025

[16] Amani, Mohammad, Pouria Amani, Alibakhsh Kasaeian, Omid Mahian, and Somchai Wongwises. "Thermal conductivity measurement of spinel-type ferrite MnFe2O4 nanofluids in the presence of a uniform magnetic field." Journal of Molecular Liquids 230 (2017): 121-128.

https://doi.org/10.1016/i.molliq.2016.12.013

[17] Bellos, Evangelos, and Christos Tzivanidis. "Thermal analysis of parabolic trough collector operating with mono and hybrid nanofluids." Sustainable Energy Technologies and Assessments 26 (2018): 105-115. https://doi.org/10.1016/i.seta.2017.10.005

[18] Sekrani, Ghofrane, and Sébastien Poncet. "Further investigation on laminar forced convection of nanofluid flows in a uniformly heated pipe using direct numerical simulations." Applied Sciences 6, no. 11 (2016): 332. https://doi.org/10.3390/app6110332 
[19] Sidik, Nor Azwadi Che, Isa Muhammad Adamu, Muhammad Mahmud Jamil, G. H. R. Kefayati, Rizalman Mamat, and G. Najafi. "Recent progress on hybrid nanofluids in heat transfer applications: a comprehensive review." International Communications in Heat and Mass Transfer 78 (2016): 68-79. https://doi.org/10.1016/i.icheatmasstransfer.2016.08.019

[20] Babu, JA Ranga, K. Kiran Kumar, and S. Srinivasa Rao. "State-of-art review on hybrid nanofluids." Renewable and Sustainable Energy Reviews 77 (2017): 551-565. https://doi.org/10.1016/i.rser.2017.04.040

[21] Bhatti, M. M., A. Riaz, L. Zhang, Sadiq M. Sait, and R. Ellahi. "Biologically inspired thermal transport on the rheology of Williamson hydromagnetic nanofluid flow with convection: an entropy analysis." Journal of Thermal Analysis and Calorimetry (2020): 1-16. https://doi.org/10.1007/s10973-020-09876-5

[22] Zainal, S., C. Tan, C. J. Sian, and T. J. Siang. "ANSYS simulation for Ag/HEG hybrid nanofluid in turbulent circular pipe." Journal of Advanced Research in Applied Mechanics 23, no. 1 (2016): 20-35.

[23] Salim, Salim M., and S. Cheah. "Wall Y strategy for dealing with wall-bounded turbulent flows." In Proceedings of the international multiconference of engineers and computer scientists, vol. 2, pp. 2165-2170. 2009.

[24] Manjunatha, S., B. Ammani Kuttan, S. Jayanthi, Ali Chamkha, and B. J. Gireesha. "Heat transfer enhancement in the boundary layer flow of hybrid nanofluids due to variable viscosity and natural convection." Heliyon 5, no. 4 (2019): e01469. https://doi.org/10.1016/i.heliyon.2019.e01469

[25] Aghaei, Alireza, Ganbar Ali Sheikhzadeh, Majid Dastmalchi, and Hamed Forozande. "Numerical investigation of turbulent forced-convective heat transfer of Al2O3-water nanofluid with variable properties in tube." Ain Shams Engineering Journal 6, no. 2 (2015): 577-585. https://doi.org/10.1016/i.asej.2014.11.015

[26] Kalteh, Mohammad, Abbas Abbassi, Majid Saffar-Avval, and Jens Harting. "Eulerian-Eulerian two-phase numerical simulation of nanofluid laminar forced convection in a microchannel." International journal of heat and fluid flow 32, no. 1 (2011): 107-116. https://doi.org/10.1016/i.ijheatfluidflow.2010.08.001

[27] Rashidi, S., M. Akbarzadeh, R. Masoodi, and E. M. Languri. "Thermal-hydraulic and entropy generation analysis for turbulent flow inside a corrugated channel." International Journal of Heat and Mass Transfer 109 (2017): 812-823. https://doi.org/10.1016/i.ijheatmasstransfer.2017.02.033

[28] Khoshvaght-Aliabadi, Morteza. "Influence of different design parameters and Al2O3-water nanofluid flow on heat transfer and flow characteristics of sinusoidal-corrugated channels." Energy conversion and management 88 (2014): 96-105. https://doi.org/10.1016/j.enconman.2014.08.042 